\title{
Editorial: Special Edition on Innovations in Cassava Processing
}

\section{$\underline{\text { Ben Bennett }}$}

In 2015 we considered small-scale cassava processing in this journal with interesting results. Since then, cassava production in sub-Saharan Africa has continued to grow by volume, and new uses and value chains are slowly emerging. But many of the founding conditions that hold the sector back remain in place. A tiny fraction of farmers have access to improved cassava planting material and varieties, or farming methods that increase productivity, despite significant investment by major donors. Rural infrastructure remains the key constraint to any leap forward in efficiency in the sector. Policy remains at odds with reality, with new calls for fixed cassava quotas in domestic foods, but very little coordinated action to support these demands.

In 2015 we considered small-scale cassava processing in this journal with interesting results. Since then, cassava production in sub-Saharan Africa has continued to grow by volume, and new uses and value chains are slowly emerging. But many of the founding conditions that hold the sector back remain in place. A tiny fraction of farmers have access to improved cassava planting material and varieties, or farming methods that increase productivity, despite significant investment by major donors. Rural infrastructure remains the key constraint to any leap forward in efficiency in the sector. Policy remains at odds with reality, with new calls for fixed cassava quotas in domestic foods, but very little coordinated action to support these demands.

What has changed is that some innovations and local equipment have started to make headway. We particularly note the growing use of flash-drying technology, high quality cassava flour (HQCF), and the recent emergence of high quality cassava peel (HQCP) as an animal feed ingredient. Although, again, scale of production and demand still hamper sectoral growth. Mechanical gari production is developing rapidly, especially in Nigeria. Bioethanol production is still in its infancy, but more investment seems likely, particularly in the beverage sector where high returns are possible. The inclusion of cassava in locally made animal feeds, a driving force for the take-off of cassava value chains in countries such as Thailand and Vietnam, is still disappointingly low.

The theme of this Special Edition, split over two editions of Food Chain, is about driving productivity in the cassava sector by increasing the scale and scope of cassava utilization. This theme responds to the continuing disjunction between efforts to improve productivity of smallscale cassava farmers and the availability of suitable cassava processing industries to provide a steady income for farmers that invest in productivity. 
Some of the papers in this issue were first presented at the IFAD-funded CassavaTech2017 Conference, held in Lagos in November 2017, where national and regional researchers shared research and best practice in the cassava post-harvest field.

In their paper on the impact of mechanization, Grace Muinga and George Marechera show the strong positive correlation between farmer mechanization and income gains. Paradoxically, labour shortages in rural Africa will constrain cassava development as higher yields need more effort to manage.

We have two papers from Irekhore et al. and Ande et al, that confirm the benefits of cassava as a poultry feed ingredient. Using cassava and its largely discarded by-product, cassava peels, for this sector makes a lot of sense.

Cassava value chains in rural Africa are highly gendered and we are only recently beginning to understand the implications of this. Petra Abdulsalam-Saghir and Oluwabunmi Oluwatosin Adeuyi's work on how households utilize cassava peels highlights how important gender differentiation will be, as cassava processing opportunities and new pre- and postharvest technologies are rolled out.

Finally, in the paper from Adegbola et al., we see the emergence of academic interest in the efficiency of new drying technologies, particularly the flash-dryer, with its promise of a costeffective, energy-efficient alternative to the uncertainty of sun-drying. The ability of local producers to make and service this type of postharvest equipment will be important to the development of the cassava sector across Africa, but is largely neglected by donors, academics, and policy makers alike. This issue will be considered in more depth in the second part of the Special Edition on Cassava Processing. 